\title{
Economia da Informação, Redes Eletrônicas e Regulação: Elementos de Análise
}

\author{
Information economics, electronic networks \\ and regulation: elements of analysis
}

ALAIN HERSCOVICI *

\begin{abstract}
RESUMO: Este trabalho tem como objetivo analisar os diferentes componentes da chamada nova economia. A primeira parte, essencialmente teórica, trata das várias concepções sobre a natureza e o papel da informação no funcionamento dos mercados. A segunda parte mostra as características microeconômicas das redes eletrônicas, avaliando suas propriedades competitivas. Na terceira parte, após delinear o atual regime de acumulação, é discutida a relação entre o desenvolvimento de redes e a implementação de um novo modo de regulação. Quanto a este assunto, são oferecidas interpretações alternativas do paradoxo de Solow.

PALAVRAS-CHAVE: Assimetrias de informação; economia de redes; externalidades; paradoxo de Solow.

ABSTRACT: This paper aims at analyzing the different components of the so-called new economy. The first part, essentially theoretical, deals with the various conceptions on both the nature and role of information in the working of markets. The second part shows the microeconomic characteristics of electronic networks, evaluating its competitive properties. In the third part, after having outlined the current accumulation regime, the relationship between networks development and the implementation of a new mode of regulation are discussed. As regards this matter, alternative interpretations of Solow paradox are offered. KEYWORDS: Information asymmetries; network economics; externalities; Solow's paradox. JEL Classification: D82; L86; O38.
\end{abstract}

Este trabalho propõe-se a analisar os diferentes componentes da chamada nova economia, e isso a partir de perspectivas diferenciadas. A dupla natureza econômica dessas redes ressalta o fato que elas são o objeto de tendências contraditórias: por um lado, elas se traduzem por uma disseminação e uma "publicização" da Informação e permitem o surgimento de novas modalidades de concorrência e

\footnotetext{
* Departamento de Economia da Universidade Federal do Espírito Santo - UFES, Vitória/ES, Brasil. E -mail: alhersco.vix@zaz.com.br. Submetido: abril 2002; aceito: fevereiro 2003.
} 
de apropriação de determinadas informações. Por outro, elas se caracterizam por importantes processos de privatização da Informação e de concentração econômica, no âmbito de redes fechadas ou semifechadas. No decorrer deste trabalho, tentarei ressaltar essa dinâmica, na sua dimensão dialética.

Numa primeira parte analisarei, a partir de uma abordagem essencialmente teórica, as diferentes concepções relativas à natureza econômica da Informação e ressaltarei os limites de certas concepções oriundas do mainstream. Numa segunda parte, farei uma análise meso e microeconômica dessas redes e mostrarei por que elas não correspondem à situações concorrenciais. Finalmente, no âmbito de uma análise macroeconômica, mostrarei como essas redes se inserem na lógica do regime de acumulação sob dominante financeira e, à luz desses elementos, como é possível fornecer explicações alternativas no que diz respeito ao paradoxo de Solow.

\section{A NATUREZA ECONÔMICA DA INFORMAÇÃO: O DEBATE TEÓRICO}

\section{Uma primeira abordagem}

\section{O debate teórico}

As diferentes concepções da natureza da Informação representam uma parte essencial do debate na ciência econômica, a partir dos anos 70; enquanto, no âmbito da abordagem do mainstream, as análises se relacionam diretamente com as imperfeições da informação, imperfeições estas definidas em relação à norma walrasiana, as diferentes análises heterodoxas ressaltam a multidimensionalidade da informação e de suas modalidades de apropriação.

Assim, os teóricos do mainstream, mais especificamente aqueles que trabalham com a teoria das expectativas racionais, estudam situações nas quais existem imperfeições da informação: parte dessa informação deixa de ser transmitida gratuitamente por meio do sistema de preços e vai adquirir um preço ${ }^{1}$. Nesse nível, é preciso fazer dois tipos de observações: (a) no que diz respeito à teoria das expectativas racionais, por exemplo, apesar da informação ser incompleta, todos os agentes têm as mesmas modalidades de acesso à informação disponível. Não há assimetrias da Informação. (b) Assim os agentes agem racionalmente no que diz respeito às modalidades de aquisição da informação: compram informação até o custo marginal da última informação comprada ser igual à sua utilidade marginal. Maximizam assim a utilidade da informação.

Minhas críticas se relacionam com os seguintes pontos:

i) a argumentação do mainstream parte do pressuposto segundo o qual o agente pode avaliar, ex-ante, a utilidade da informação. Não obstante, a informação

\footnotetext{
${ }^{1}$ Kenneth J. Arrow, "Limited Knowledge and Economic Analysis”, American Economic Review, March 1974: 7.
} 
pode ser concebida como um objeto multidimensional ${ }^{2}$, sua utilidade dependendo de variáveis institucionais, cognitivas, sociais e históricas; a utilidade de determinada informação não pode ser definida ex ante independentemente dessas variáveis. Conseqüentemente, não é possível maximizar o comportamento relativo à compra da informação. A esse respeito, é interessante observar que a análise neoclássica parte dos mesmos pressupostos que a teoria da informação da maneira como ela foi expressa por Shanon, por exemplo: o mundo é ergódico e é possível determinar o valor da informação independentemente do contexto no qual ela foi elaborada e no qual é utilizada.

ii) Em última instância, na tradição neoclássica, o mercado é concebido comouma instância abstrata ${ }^{3}$ pelo fato de supor que toda a informação necessária é divulgada gratuitamente pelo sistema de preços e que não existem custos irreversíveis. A análise neoclássica é uma construção teórica na qual, numa situação de concorrência pura e perfeita (CPP), o jogo de mercado representa a solução, social e economicamente falante, mais eficiente: o campo de investigação da economia é concebido como um campo social totalmente independente dos outros campos sociais. Todos os elementos não-mercantis que permitem explicar as modalidades concretas de existência e de funcionamento dos mercados são excluídos da análise e considerados com extra-econômicos.

No âmbito de uma abordagem alternativa, o mercado não é um lugar no qual agentes homogêneos ${ }^{4}$ se encontram e maximizam certas funções a partir de uma racionalidade substantiva definida fora de qualquer norma social e no qual o sistema de preços fornece a informação necessária. Da mesma maneira, existem custos de transação, ou seja, custos para poder ter acesso a esses mercados; a própria existência de tais custos faz com que as decisões dos agentes se tornam irreversíveis.

A economia das convenções vai no mesmo sentido ${ }^{5}$; ela tenta resolver os problemas ligados à heterogeneidade dos agentes, às modalidades de coordenação não mercantis, da maneira como esses processos atuam nos mercados concretos: "a convenção é uma forma que permite coordenar os interesses contraditórios que derivam de lógicas opostas mas que têm necessidade de estarem juntas para serem

\footnotetext{
${ }^{2}$ A este respeito, ver, por exemplo: Favereau, Olivier, "Notes sur la théorie de l'information à laquelle pourrait conduire l'économie des conventions", in L'Economie de l'information, sous la direction de Pascal Petit, La Découverte, Paris, 1998: 229: “(...) o contexto da Informação condiciona significativamente o conteúdo da informação", e Jean-Louis Le Moigne, "La modélisation systémique de l'Information", in L'Economie de l'information, op. cit., p. 56.

${ }^{3}$ K. Arrow, op. cit., p. 4

${ }^{4} \mathrm{~K}$. Arrow, "De la rationalité de soi et des autres dans un système économique", in Théorie de l'Information et des organisations, Edité et présenté par Thierry Granger, Dunod, Paris 2000: 246-247.

${ }^{5}$ A esse respeito, ver Alain Rallet, "A teoria das convenções segundo os economistas" in Nexos, vol. I, $\mathrm{n}^{\circ}$ 2, dezembro de 1999, e Salvador, Olivier Favereau, "L'économie des conventions: son objet, sa contribution à la science économique", Problèmes économiques, $\mathrm{n}^{\circ}$ 2167, 21 Mars 1990, La Documentation Française, Paris.
} 


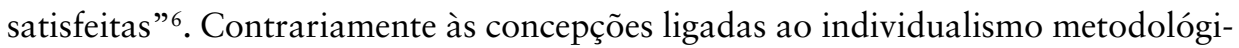
$\mathrm{co}$, as concepções heterodoxas se propõem a analisar esses processos de socialização e a mostrar como estes cumprem um papel fundamental na regulação meso $e$ macroeconômica. De um ponto de vista teórico, se o sistema de preços não constitui um sinal adequado que permita diminuir os diferentes desequilíbrios nem para coordenar a atuação dos agentes econômicos, a existência de instituições, seja o Estado, as formas institucionais ou as convenções, é necessária para conter essa instabilidade e para assegurar a regulação macroeconômica ${ }^{7}$.

Os limites das análises baseadas nos conceitos de maximização e de racionalidade individual foram apontados, entre outros, pelos "velhos" institucionalistas. No que diz respeito à Informação, Hodgson ${ }^{8}$ ressalta o fato de que sua apropriação pressupõe a existência de determinados processos cognitivos; esses processos, intrinsecamente ligados à existência de instituições, de regras e de costumes, permitem especificar as modalidades de apropriação da Informação e explicar as modalidades de "enculturação" (enculturation, em inglês) necessárias à sua descodificação. Os questionamentos levantados pelas diferentes análises de cunho heterodoxo podem ser resumidos da seguinte maneira:

i) A coordenação meso e macroeconômica não é postulado, mas constitui umdos objetos centrais da análise econômica: a economia das convenções e a economia institucionalista, nas suas versões heterodoxas, coloca esse problema e ressalta o fato de que o funcionamento concreto dos mercados, assim como as modalidades de coordenação, são o produto das articulações entre elementos mercantis e outros não mercantis. São essas articulações que determinam as especificidades sociais e históricas dos mercados concretos.

ii) Enquanto o mainstream concebe a informação como um bem que, no âmbito de um universo ergódico, por si mesmo, permite reduzir a ignorância relativa ao futuro, as análises heterodoxas chegam a conclusões radicalmente diferentes: (a) a Informação não pode ser concebida independentemente de determinadas instituições e convenções sociais, (b) conseqüentemente, não existe um valor intrínseco que pode ser definido ex ante. De fato, essa análise ressalta a importância da contextualização que caracteriza e determina o valor da informação e sua utilidade diferenciada.

\section{A natureza econômica da Informação}

A informação (e seria possível fazer o mesmo tipo de observações no que diz respeito ao conhecimento) se caracteriza pela não-exclusividade e pela não-rivalidade, pelo menos parciais: a mesma informação pode ser utilizada por vários agen-

\footnotetext{
${ }^{6}$ Alain Rallet, op. cit., p. 112.

${ }^{7}$ Alain Herscovici, “Economia do desequilíbrio, sistema de preços e instituições: elementos de análise", in Ensaios FEE, vol. 23, $\mathrm{n}^{\circ}$ 1, 2002, Porto Alegre.

${ }^{8}$ Hodgson, Geoffrey M., “The Approach of Institucional Economics”, Journal of Economic Litterature, vol. 36, Issue 1, March 1998, pp. 171 e 183.
} 
tes econômicos. Da mesma maneira, a utilização de determinada informação por um agente econômico não implica que ela não esteja disponível para outros agentes? . Por "natureza", a informação apresenta características ligadas a seu caráter indivisível: ela produz externalidades positivas e corresponde a situações não concorrenciais à medida que existem externalidades e rendimentos crescentes ${ }^{10}$. No caso de a informação ser produzida a partir de modalidades privadas, é preciso instaurar direitos de propriedades para limitar suas modalidades de apropriação a fim de poder rentabilizar os custos irreversíveis: aparecem, assim, divergências entre o rendimento privado e o rendimento coletivo da informação.

Segundo Arrow, uma falha (ou imperfeição) de mercado aparece quando existem custos de transação, ou seja, custos que as empresas têm que assumir para poder atuar nos diferentes mercados ${ }^{11}$. Esses custos se relacionam diretamente com (a) os custos de exclusão, (b) os custos de informação e de comunicação relativos à divulgação e à aprendizagem dos preços pelos quais as transações podem ser efetuadas, e (c) os custos de desequilíbrio associados ao tempo necessário para calcular a alocação ótima. A partir dessa definição, o conceito de menu costs desenvolvido pelos novos keynesianos representa um custo de transação. A existência de tais custos tem dois tipos de implicações: na perspectiva do mainstream, quanto maior esses custos, menor a flexibilidade dos preços e maior a amplitude das flutuações econômicas ${ }^{12}$. Por outro lado, eles representam uma perda em termos de bem-estar coletivo.

\section{As diferentes formas de assimetria da Informação e a análise de Akerlof e Stiglitz}

i) De um ponto de vista mais geral, a contextualização de qualquer tipo de informação é um processo que ressalta as modalidades intrinsecamente diferenciadas da apropriação da informação pelos diferentes agentes; ii) se, por outro lado, a informação é assimilada ao conhecimento e/ou ao progresso técnico, na perspectiva marxiana e schumpeteriana, a inovação tecnológica é um processo intrinsecamente assimétrico: explica o aparecimento de rendas temporárias de monopólio por parte dos agentes inovadores assim como o diferencial de taxa de lucro e de estrutura de custos no seio de uma mesma indústria ${ }^{13}$; iii) finalmente, é importante observar que, no âmbito de uma perspectiva keynesiana, a homogeneidade dos

\footnotetext{
${ }^{9} \mathrm{~K}$. Arrow, "L'économie de l'information: un exposé", in Théorie de l'Information et des organisations, Edité et présenté par Thierry Granger, Dunod, Paris, 2000, p. 83.

${ }^{10}$ Idem, p. 89.

${ }^{11} \mathrm{~K}$. Arrow, "Potentialités et limites du marché dans l'allocation des ressources", in Théorie de l'Information et des organisations, op. cit., p. 78.

${ }^{12}$ N. Gregory Mankiw, "Small menu cand large business cycles: a macroeconomic model of monopoly", Quartely Journal of Economics 100, 1985.

${ }^{13}$ Alain Herscovici, Dinâmica macroeconômica: uma interpretação a partir de Marx e de Keynes, Educl Edufes, São Paulo, 2002.
} 
comportamentos, das expectativas e, conseqüentemente, das informações a partir das quais essas expectativas são elaboradas não permite explicar a realidade da troca: o exemplo da demanda de moeda por motivo de especulação ilustra perfeitamente esta tese ${ }^{14}$.

A Economia da Informação liderada por Akerlof e Stiglitz ${ }^{15}$ mostra que o sistema de preços não constitui um sinal eficiente e que, contrariamente ao mainstream, existem assimetrias da informação. As assimetrias da informação são estudadas em função da natureza do sistema de preços de mercado, das especificidades dos bens e dos comportamentos dos agentes.

i) Em um universo no qual existem custos para adquirir certos tipos de infor-mações, existem dois tipos de agentes: os que vão pagar esse custo (os informados) e os que não vão procurar esta informação (os não-informados). O equilíbrio se caracteriza pelo fato de que o sistema de preços permite transferir a informação dos informados para os não-informados; a informação seria um bem indivisível e produziria, assim, externalidades positivas. A eficiência do sistema de mercado permite atingir esse equilíbrio.

Não obstante, aparece o seguinte paradoxo: se existem arbitragens perfeitas, não há interesse, por parte dos informados, em adquirir essa informação: seu custo é igual à sua utilidade marginal. A utilidade esperada da população informada é igual à utilidade esperada da população não-informada. A conclusão lógica é que o sistema de preços não divulga a totalidade da informação disponível para a totalidade da população: essas assimetrias da informação permitem a apropriação de uma renda extra, por parte dos agentes informados. A partir do momento em que o sistema de preços não redistribui a totalidade da informação disponível, que existem assimetrias da informação, o mercado não constitui um mecanismo socialmente eficiente: os ganhos realizados pelos agentes informados são privados e essa situação não corresponde a um ótimo de Pareto.

ii) Em certos casos, o sistema de preços não tem condições de fornecer todasas informações a respeito da qualidade dos produtos. O consumidor, a partir de sua prática de consumo, passa progressivamente a conhecer as qualidades do produto ou do serviço (experience goods) ou vai ter que adquirir informações suplementares a respeito daquele produto (search goods). Se considerarmos que os produtores têm as informações relativas aos produtos e aos serviços que eles estão vendendo, e se os consumidores não possuem a totalidade dessa informação, existem assimetrias da informação e o sistema de preços não permite realizar uma alocação ótima dos recursos.

No caso dos experience goods, a informação é geralmente incompleta, por natureza: o consumidor não experimentará a totalidade dos bens equivalentes e

\footnotetext{
${ }^{14}$ John Maynard Keynes, A teoria geral do emprego, do juro e da moeda. São Paulo: Atlas, 1990: 139.

${ }^{15}$ Ver, respectivamente, S.J. Grossman and J.E.Stiglitz, "Information and competitive price system", American Economic Review, May 76, vol. 66, n 2, e G. Akerlof, "The market for 'lemons': qualitative uncertainty and the market mechanism”, Quarterly Journal of Economics, Aug.1970, 89.
} 
não maximizará seu excedente. No caso dos search goods, é possível admitir que a procura por informação lhe permite conhecer todas as informações relativas aos produtos $^{16}$. O consumidor não-informado considera que a procura, por parte dos consumidores informados, é uma garantia no que diz respeito à qualidade dos produtos e que o preço reflete essa qualidade; neste caso, a informação está sendo divulgada por meio do sistema de preços dos informados para os não-informados. Ao contrário, é possível imaginar situações nas quais o preço não reflete a qualidade do produto; se um preço alto implica a qualidade do produto, os produtores que produzem bens com qualidade inferior podem utilizar essa estratégia e o sistema de preços deixa de constituir um sinal de qualidade ${ }^{17}$.

iii) Uma situação de seleção adversa existe quando, ex ante, um das partes detém mais informações que a outra: existe uma renda informacional, por parte de certos agentes, que permite se apropriar de uma renda extra. O risco moral aparece quando, no âmbito de determinado contrato (de trabalho, por exemplo), ex post, o comportamento do indivíduo contratado não pode ser totalmente observado: o mercado de seguros é característico desse tipo de situação. Essas análises se aplicam, igualmente, aos mercados financeiros, de serviços e do trabalho. Essas assimetrias da informação permitem a apropriação de rendas por parte dos agentes que detêm informações relevantes: o sistema de preços não permite igualar, sistematicamente, oferta e demanda, e a utilidade social da informação é diferente de sua utilidade privada.

\subsection{Equilíbrio concorrencial, sistema de preços e informação}

Uma modelagem simples permite sintetizar as abordagens ligadas à economia da informação. $\mathrm{O}$ mecanismo geral é o seguinte ${ }^{18}$ :

$\mathrm{E}_{1}=\mathrm{U}_{1}-\mathrm{p}_{1}-\mathrm{c}_{1}$

$\mathrm{E}_{2}=\mathrm{U}_{2}-\mathrm{p}_{2}-\mathrm{c}_{2}$

E representa o excedente líquido do consumidor, $\mathrm{U}$, a utilidade total esperada, p e c, respectivamente, o preço dos bens e serviços e o custo pago pela informação. $\mathrm{O}$ índice 1 se relaciona com os consumidores pouco informados, o índice $2 \mathrm{com}$ os informados.

Esse mecanismo pode ser interpretado da seguinte maneira: no equilíbrio, $\mathrm{E}_{1}$ $=\mathrm{E} 2$, ou seja, $\mathrm{U} 1-(\mathrm{p} 1+\mathrm{c} 1)=\mathrm{U} 2-(\mathrm{p} 2+\mathrm{c} 2)(1)$. Os preços variam entre o preço de concorrência pura e perfeita $\left(\mathrm{p}^{*}\right)$ e o preço de monopólio $(\mathrm{pm})$.

É possível deduzir as seguintes conclusões:

i) para $c_{2}$ e $c_{1}$ superiores a 0 , não há equilíbrio concorrencial pelo fato de não existir um preço único; ii) no equilíbrio concorrencial, o excedente esperado

\footnotetext{
${ }^{16}$ Steve Salop, "Information and monopolistic competition", American Economic Review, vol. 66, n 2, May 1976: 241.

${ }^{17}$ G. Akerlof, op. cit.

${ }^{18}$ Essa modelagem provém da análise de Salop, op. cit.
} 
por parte dos consumidores pouco informados é igual ao excedente esperado por parte dos consumidores informados; U2 - U1 é compensada por p2+c2 - $(\mathrm{p} 1+\mathrm{c} 1)$, tendo em vista que $\mathrm{p} 1>\mathrm{p}_{2}$ e $\mathrm{c}_{2}>\mathrm{c}_{1}$. Enquanto os custos da informação são, obviamente, mais elevados para os agentes informados, os preços que esses pagam são menores.

Por outro lado, temos as seguinte situações possíveis:

i) se $\mathrm{c}_{2}=\mathrm{c}_{1}=0$, estamos numa situação concorrencial na qual $\mathrm{p}_{1}=\mathrm{p}_{2}=\mathrm{p}^{*} \mathrm{e}$, conseqüentemente, $\mathrm{U}_{1}=\mathrm{U}_{2}$ ii) se $\mathrm{c}_{2}>0$ e $\mathrm{c}_{1}=0$, e se a proporção de agentes informados for relativamente importante, temos que $U_{2}-p_{2}-c_{2}=U_{1}-p_{1}$. Os consumidores não informados se beneficiam das externalidades positivas produzidas pelos consumidores informados e o equilíbrio é competitivo iii) se $c_{2}>c_{1}>0$, o equilíbrio não é competitivo pelo fato de existir mais de um preço. Tratando-se dos search goods, o equilíbrio é realizado a partir de dois preços; tratando-se de experience goods, por definição, não existe informação completa. Neste caso, existem tantos preços quantos tipos de consumidores.

Finalmente, esse mecanismo permite entender por que, no caso de $c_{2}>c_{1}>0$, o equilíbrio não é concorrencial com apenas um preço. Uma firma pode aumentar seu preço acima do preço concorrencial sem perder consumidores: para os consumidores pouco informados, o aumento do preço acima do preço de CPP não se traduz por um aumento dos custos ligados à busca de informação, já que isso diminuiria a utilidade total esperada. Por outro lado, uma queda dos preços abaixo de pm incita os agentes a comprar mais informações para descobrir um preço mais baixo. Assim seria possível explicar o ciclo econômico pelo fato de os preços oscilarem entre um piso e um teto.

\section{A ECONOMIA DAS REDES ELETRÔNICAS}

\section{As diferentes concepções da concorrência}

1. Uma primeira concepção assimila a concorrência ao modelo de concorrência pura e perfeita; é a partir dessa concepção que vão ser identificadas determinadas imperfeições de mercado, seja em termos de rigidez (relativa) dos preços, seja em termos de "incompletude" da informação ou de estrutura dos custos (os rendimentos crescentes).

Para os teóricos da nova economia clássica, as redes eletrônicas são concebidas como um meio que permite diminuir essas imperfeições, de tal maneira que o sistema alcance mais "rapidamente" a posição de equilíbrio estável. No que diz respeito à função de oferta de Lucas, os agentes confundem o aumento do nível geral dos preços com o aumento dos preços relativos de sua produção; neste caso, uma melhor divulgação da informação deveria permitir reduzir essas imperfeições e voltar mais rapidamente para a posição de equilíbrio, na qual o produto real é igual ao produto natural. Da mesma maneira, os custos de menu (menu costs) são os custos que as empresas têm que pagar para informar os agentes de uma modifica- 
ção de seus preços. Quando esses custos são altos, as empresas não modificam seus preços e isso explica as flutuações econômicas; uma diminuição desses custos deve, conseqüentemente, restabelecer a flexibilidade dos preços e diminuir, assim, a amplitude das flutuações econômicas.

Essas análises partem do fato de que quanto mais concorrenciais são os mercados e quanto menos imperfeições a informação apresenta, mais veloz é o processo de ajustamento rumo ao equilíbrio, o qual corresponde a uma situação de ótimo social. A função das Tecnologias da Informação e da Comunicação (TIC) consistiria em diminuir os custos ligados à redução dessas imperfeições e em tornar, assim, os mercados mais concorrenciais: no âmbito de uma lógica “liberal”, esse tipo de análise justifica as diferentes políticas de flexibilização dos mercados pelo fato de diminuir os custos de transação e de restaurar, assim, a flexibilidade dos preços $^{19}$.

2. Uma outra concepção da concorrência se define pelo grau de contestabilidadedos mercados: parte da idéia segundo a qual a concorrência pode se dar por meio de processos diferentes dos ligados a um estado de concorrência pura e perfeita, notadamente a partir de situações monopolista ou oligopolista ${ }^{20}$. Um mercado é perfeitamente contestável a partir do momento em que "a entrada é totalmente gratuita e a saída não implica custos suplementares" ${ }^{21}$. A ausência de barreiras à entrada significa que uma firma que queira entrar nesse mercado não vai sofrer prejuízos em termos de condições de acessibilidade à tecnologia ou em termos de taxa de lucro; a ausência de barreiras à saída implica que seja possível revender o capital sem perda e que não haja custos irreversiveis.

A teoria dos mercados contestáveis tem por objetivo ampliar o conceito de concorrência pura e perfeita: essa teoria pode ser considerada como uma extensão mais realista do processo da mão invisível, ou seja, da eficiência do mercado:

i) Em um mercado contestável, não existe lucro extra; qualquer lucro extra se traduziria pela intensificação da pressão do mercado, pela entrada de novas firmas atraídas por esse lucro extra e pelo desaparecimento deste.

b) Os preços são iguais aos custos marginais e o equilíbrio é do tipo Pareto equilíbrio; qualquer ineficiência em termos de aumento dos custos acima do custo médio intensificaria a pressão do mercado. Para eliminar essa pressão de mercado, as firmas insiders têm que diminuir o preço até este se igualar com o custo marginal.

\footnotetext{
${ }^{19}$ Davidson, Paul, "Colocando as evidências em ordem: macroeconomia de Keyne versus velho e novo keynesianismo", in Macroeconomia moderna. Keynes e a Economia Contemporânea, org. G.T. Lima, J. Sicsú, L. F. de Paula, Campus, Rio de Janeiro, 1999: 59.

${ }^{20}$ W. Baumol, "Contestable markets: an uprising in the theory of industry structure", American Economic Review, vol. 72, nº 1, 1982.

${ }^{21}$ Idem, p. 3.
} 


\section{Economia de redes e concorrência}

\section{As principais características}

Do ponto de vista econômico, uma rede apresenta as seguintes características:

i) Os consumidores se aproveitam de um efeito de clube; quanto maior o número de participantes na rede, maior a qualidade do serviço à disposição de cada um desses participantes. A telefonia fixa apresenta tais externalidades de demanda.

ii) No que concerne à produção, existem economias de escala como, por exemplo, no caso do monopólio natural.

iii) A existência de custos irreversíveis faz com que seja preciso limitar o aces-so a esse tipo de informação para poder rentabilizar o investimento inicial; a partir dos direitos autorais ou da legislação relativa à propriedade industrial, vai ser instaurado um direito de entrada. Assim, por razões econômicas, parte dessa informação tem que permanecer privada.

As redes eletrônicas apresentam características que se afastam da CPP; geralmente, a estrutura de custos permite assimilar essas empresas aos monopólios naturais. Os custos fixos são importantes e se relacionam diretamente com as atividades de pesquisa e desenvolvimento, ou com a implementação de uma infra-estrutura de base; eles são, geralmente, irreversíveis. Os custos variáveis ligados à reprodução/ distribuição do produto são muito baixos; no que diz respeito à produção de um software, por exemplo, os custos ligados à concepção do programa são custos fixos enquanto os custos de reprodução são negligenciáveis. Trata-se de um monopólio natural; esse monopólio não pode igualar custo marginal e receita marginal e o equilíbrio assim realizado não é um ótimo de Pareto ${ }^{22}$. No caso de uma monoprodução, o custo médio do monopólio é inferior àquele de uma empresa que só atende a parte daquela demanda ${ }^{23}$; a economia de redes se caracteriza pela sub-aditividade dos custos. Assim, se para poder rentabilizar certos custos irreversíveis importantes, é preciso haver renda de monopólio. Neste caso, mesmo na concepção neoclássica, o equilíbrio de mercado não corresponde a uma situação de ótimo social e é preciso haver intervenção do Estado para "corrigir" essas imperfeições de mercado ${ }^{24}$.

No âmbito de uma abordagem em termos de economia das redes, uma outra dimensão relativa à concorrência existe em relação aos custos de interconexão: cada agente tem que ter as mesmas condições de acesso aos diferentes serviços e à

\footnotetext{
22 Daniel Cohen, Michèle Debonneuil, "L'économie de la nouvelle économie”, in Nouvelle Economie, Conseil d'Analyse Economique, La Documentation Française, Paris, 1998, p. 33.

${ }^{23}$ Nicolas Curien, Economie des réseaux, La Découverte, Paris, 2000, p. 44.

24 Bruno Amable e Pascal Petit "Ajustamento estrutural e política industrial: uma abordagem regulacionista", in Bruno Théret e José Carlos de Souza Braga (orgs.), Regulação econômica e globalização, IE/Unicamp, Fundap, Campinas, 1998, p. 358.
} 
operadora histórica ${ }^{25}$; as práticas discriminatórias implementadas pelas empresas americanas, no que diz respeito às conexões com as redes internacionais, mostram que essa economia não é concorrencial ${ }^{26}$.

Os custos de interconexão representam um elemento fundamental no que diz respeito à concorrência: o problema é particularmente importante no que concerne aos custos relativos à interconexão com certas operadoras históricas, sejam elas públicas ou privadas. Esse problema está presente na economia das telecomunicações e da Internet; o unbundling consiste em restaurar a concorrência no mercado das telecomunicações ${ }^{27}$ pelo fato de reduzir as barreiras à entrada representadas pelos custos irreversíveis ligados ao financiamento da infra-estrutura. As diferentes modalidades de compartilhamento da infra-estrutura que pertence à operadora histórica constituem elementos que atuam para intensificar a concorrência, tornar as redes mais abertas, diminuir, por parte dos participantes, os custos irreversíveis e aumentar, assim, o grau de contestabilidade dos mercados.

Não obstante, no que diz respeito ao setor das telecomunicações, a situação é totalmente diferente: as firmas americanas, que se aproveitam de importantes economias de escala, conseguiram desviar o tráfico internacional em seu favor. Por outro lado, elas praticam uma forte discriminação no que concerne às tarifas de conexão praticada para as firmas americanas e as estrangeiras, o que inibe qualquer forma de concorrência. A desregulamentação operada no mercado americano da telefonia e a exacerbação da concorrência interna permitiram realizar diminuições importantes das tarifas praticadas pelas operadoras; a partir das técnicas de $h u b$ e de call-back, houve desvios importantes do tráfego internacional, em favor dos Estados Unidos. Isso permitiu realizar importantes economias de escalas, enfraqueceu a posição das operadoras estrangeiras e tornou cada vez mais difícil a manutenção das políticas de serviço público baseadas na prática dos subsídios cruzados ${ }^{28}$. O desvio e a concentração de tráfego se acentuou em favor dos Estados Unidos. Isso se estendeu para as conexões com a Web; os custos de conexão praticados pelas firmas européias são vinte vezes superiores aos custos equivalentes praticados pelas firmas americanas. Enquanto o tráfego ligado à Internet já ultrapassou o tráfego telefônico mundial, as treze primeiras firmas fornecedoras desse tipo de conexão são americanas ${ }^{29}$; não obstante, os custos de conexão a serem pagos pelas firmas estrangeiras são muito mais altos que os praticados para as firmas america-

\footnotetext{
${ }^{25}$ Nicolas Curien, op. cit., p. 91.

${ }^{26}$ Alain Herscovici, César Bolaño, Daniel Vasconcelos, Economia política da Internet, no prelo.

${ }^{27}$ Hamilton de Moura Ferreira Júnior, José Rogério da Costa Vargens Filho, "O preço do unbundling no Brasil. Concorrência e universalização na indústria de telecomunicações”, Revista de Economia Contemporânea, vol. 6, $\mathrm{n}^{\circ}$ 1, janeiro-junho de 2002, Rio de Janeiro.

${ }^{28}$ Ver Philippe Quéaud, "Les termes inégaux de l'échange électronique”, Le Monde Diplomatique, Février 1999.

${ }^{29} \mathrm{Idem}$
} 
nas. É possível afirmar assim que existe uma subvenção mundial dos fornecedores de acesso não-americanos em favor dos fornecedores de acesso americanos ${ }^{30}$.

\subsection{A dupla natureza das redes eletrônicas}

O efeito de clube não caracteriza o conjunto das atividades ligadas à Internet: ele só seria válido no que concerne à informação gratuita; no que diz respeito à informação privada ou semiprivada, certas características qualitativas dependem da limitação das modalidades de acesso à essa informação. No caso da informação estratégica, a qual se relaciona mais com as relações intra e interfirmas, o valor da informação depende diretamente do número restrito dos participantes; por isso, é preciso limitar suas modalidades de acesso.

No que diz respeito à informação gratuita e pública, estamos na presença de externalidades quantitativas de demanda: quanto maior o número de participantes, maiores essas externalidades positivas. É possível falar assim em redes abertas à medida que se trata de maximizar o número de participantes. $O$ clube é aberto: sua constituição se explica a partir da interdependência dos indivíduos na base de relações que se situam, parcialmente, fora do mercado ${ }^{31}$. O clube é aberto e inclusivo à medida que ao aumento dos membros do clube corresponde um aumento da utilidade do serviço proposto, em função das externalidades positivas de demanda.

A outra dimensão dessas redes é diretamente ligada à implementação de mercados globais, parcialmente desregulamentados. Elas constituem um dos componentes importantes da infra-estrutura desses novos mercados e estão diretamente ligadas a financeirização da economia, às relações inter e intrafirmas (intranet), às relações entre as firmas e os consumidores e às próprias modalidades de produção e de distribuição dos produtos e dos serviços. O desenvolvimento dessas redes pode ser interpretado como “(...) uma institucionalização progressiva dessas novas relações mercantis" ${ }^{2}$, a qual corresponde às modificações da estrutura dos mercados, da natureza da concorrência e das modalidades de acesso aos mercados. Assim, esse processo está modificando profundamente a organização interna das empresas, a estrutura e as modalidades de funcionamento do mercado do trabalho, a organização espacial da produção e as modalidades de acesso aos mercados ${ }^{33}$.

A informação que está sendo divulgada apresenta as seguintes características: ela é privada ou semiprivada à medida que, por razões econômicas ou estratégicas, suas modalidades de acesso têm que ser limitadas. Isso concerne tanto às informações ligadas à pesquisa quanto às ligadas às decisões estratégicas ou financeiras: a

\footnotetext{
${ }^{30}$ Ibid.

${ }^{31}$ Besson, Jean-François, Economie Publique. L'échange sans marché, PUF, Paris, 1978. p. 156 e seguinte.

32 Bruno Amable e Pascal Petit, op. cit., p. 370.

${ }^{33}$ Eric Brousseau, "Intermédiation par les réseaux: quelles institutions?”, in Mutations des Télécommunications, des Industries et des Marchés, E. Brousseau, P. Petit et Denis Phan (orgs.), ENSPTT/Economica, Paris, 1996, p. 172
} 
qualidade e o valor da informação dependem diretamente dos limites impostos no que diz respeito às suas modalidades de acesso. Aparecem assim externalidades qualitativas diretamente ligadas ao número restrito de participantes: trata-se de um efeito de congestionamento, na terminologia da economia pública. O clube é semifechado, parcialmente excludente, e esse processo corresponde a uma (re)privatização da informação.

Assim, as redes eletrônicas não podem ser concebidas apenas como redes abertas, as quais seriam sinônimas da instauração de uma "democracia digital" e de um espaço concorrencial globalizado. Parte dessas redes é de redes fechadas ou semifechadas, dentro das quais circulam informações semiprivadas. Não é possível analisar a economia da Internet unicamente a partir do primeiro aspecto, enquanto seu desenvolvimento se explica a partir dessa funcionalidade diretamente ligada à implementação dessa "nova economia". As contradições dessas redes provêem dessa dupla natureza contraditória: a utilização da Internet como uma rede aberta na qual circulam informações gratuitas é, parcialmente, incompativel com sua utilização como infra-estrutura dessa nova economia.

\section{TIC e novas formas de concorrência: o caso dos programas livres}

O caso dos programas "livres" como o Linux é particularmente interessante: a criação e o desenvolvimento de tais programas, numa certa medida, correspondem à uma redefinição da dicotomia mercantil/ não mercantil. Sob certos aspectos, isso pode igualmente ser interpretado como uma nova forma de concorrência que poderia desestabilizar os oligopólios existentes. Finalmente, esse processo corresponde a uma publicização da informação.

Um programa livre se caracteriza pelo fato de suas modalidades de acesso e de utilização não serem predeterminadas; é um programa "aberto" e evolutivo à medida que seus utilizadores podem modificá-lo e revendê-lo. Os direitos autorais relativos à arquitetura original do programa são protegidos pelo copyleft; esses direitos são cedidos gratuitamente aos utilizadores que podem revender e modificar o programa original. Não obstante, esses utilizadores não têm direitos sobre o programa assim modificado. De fato, o "código fonte" do programa faz com que o utilizador tenha à sua disposição a arquitetura global do programa: possui, integralmente, o código fonte e pode modificá-lo à vontade. O produtor original não pode mais limitar suas modalidades de acesso nem de utilização, contrariamente ao caso dos programas "fechados". Segundo certas estimativas, a parte de mercado desses programas livres no que diz respeito ao segmento dos servidores internet, chega a ser igual àquela da Microsoft ${ }^{34}$.

A produção de programas tradicionais se caracteriza pela importância dos custos fixos e pela necessidade, em função desses custos irreversíveis, de limitar as modalidades de acesso a esses programas; as rendas de monopólio correspondem

\footnotetext{
${ }^{34}$ Patrice Flichy, "Les logiciels libres: un modèle fécond", 2001 bogues, globalisme et pluralisme, Montréal, avril 2002.
} 
a essa estrutura de mercado. Em função desses custos irreversíveis, o ótimo social não corresponde ao ótimo da firma. No que diz respeito aos programas livres, as características econômicas se modificaram, para fornecer as condições econômicas para o surgimento de novas formas de concorrência:

i) As modalidades de produção e de transformação do programa são elabora-das, pelo menos parcialmente, fora da esfera mercantil; a cooperação entre os diferentes utilizadores na modificação do programa original pode ser assimilada a uma economia da dádiva ${ }^{35}$ pelo fato de permitir uma maior circulação da riqueza criada. Isso representa uma diminuição substancial dos custos ligados à concepção e às atividades de pesquisa e desenvolvimento. A diminuição desses custos fixos irreversíveis permite reduzir as rendas de monopólio que caracterizam a produção dos softwares "fechados".

ii) Isso corresponde igualmente a uma modificação da natureza da rede: enquan-to as redes tradicionais se traduzem por uma privatização de parte da informação, o desenvolvimento desses programas livres corresponde, ao contrário, a uma "abertura" maior da rede e a uma publicização da informação que circula nessa rede. a indivisibilidade do serviço é uma característica fundamental desses clubes abertos.

A partir de uma abordagem em termos de economia pública, um clube é uma associação que se cria quando o mercado não permite alcançar uma situação de ótimo, seja em função da divergência entre a racionalidade microeconômica e a função de bem-estar coletivo, seja em função da estrutura dos $\operatorname{custos}^{36}$ : em todos os casos, a constituição desse clube corresponde a uma situação na qual certas externalidades positivas são endogeneizadas e na qual o abastecimento em determinados tipos de serviços é mais eficiente fora do jogo do mercado. Criam-se, assim, relações de interdependência entre os agentes econômicos fora do mercado: neste sentido, é possível falar em articulação entre elementos mercantis e elementos nãomercantis. As atividades ligadas à coordenação dos agentes são efetuadas, pelo menos parcialmente, fora do mercado.

O clube é exclusivo quando o ganho total não depende do número de participantes: é mais eficiente limitar as modalidades de entrada naquele clube. Ao contrário, o clube é "inclusivo" quando o ganho depende, positivamente, da quantidade de participantes; neste caso, ao aumento de usuários corresponde um aumento da qualidade do serviço fornecido para cada membro desse clube ${ }^{37}$. A economia dos softwares livres corresponde a clubes inclusivos.

iii) Finalmente, nessa economia dos softwares livres, existem outros elementos que podem ser interpretados como uma intensificação da concorrência. A estrutura básica desses programas abertos é concebida de tal maneira que, por natureza, não há barreiras à entrada: a interoperabilidade e a compatibilidade entre os dife-

\footnotetext{
${ }^{35}$ Idem.

${ }^{36}$ Jean-François Besson, op. cit., p. 157.

${ }^{37}$ Idem, p. 158.
} 
rentes produtos obtidos são, por natureza, completas. Da mesma maneira, não pode existir guerra das normas.

Finalmente, coloca-se o problema relativo às relações entre esse setor e o dos programas "protegidos". As evoluções históricas das mídias permitem distinguir dois cenários possíveis: (a) o primeiro corresponde à cooperação entre o setor mercantil e o cooperativo. No âmbito de determinadas modalidades de divisão do trabalho, pode haver um equilíbrio estável entre as firmas oligopolistas e o setor cooperativo; a economia da produção fonográfica ou editorial, no início dos anos 80 , funcionava dessa maneira. O setor cooperativo não-oligopolista constitui um "viveiro" que alimenta o conjunto dessa economia ${ }^{38}$ e permite diminuir os custos ligados às atividades de pesquisa e de desenvolvimento. (b) $\mathrm{O}$ segundo corresponde à tese do conflito. Os exemplos da radiofonia, do telégrafo, dos rádios livres e das televisões locais ressaltam o fato de que, durante uma primeira fase na qual o sistema ainda não se estabilizou, aparecem várias experiências "comunitárias"; não obstante, a mercantilização dessas atividades, após uma fase relativamente curta de concorrência e de experimentações, desemboca, "naturalmente", sobre estruturas oligopolistas ou monopolistas. Assim, as potencialidades inovadoras do setor cooperativo seriam, progressivamente, absorvidas pelos oligopólios.

\section{A ANÁLISE MACROECONÔMICA}

\section{Economia "real", nova economia e TIC}

No âmbito de uma perspectiva marxista e/ou clássica, coloca-se o problema das relações entre a economia real, na qual se cria o valor e o excedente, e o conjunto das atividades improdutivas; a questão das relações entre o capital fictício e o capital produtivo constitui a chave do problema. No âmbito de um regime de acumulação sob dominância financeira ${ }^{39}$, a autonomia relativa da forma dinheiro permite entender a autonomia relativa da esfera financeira e os limites dessa autonomia em relação ao capital produtivo ${ }^{40}$.

Esses elementos permitem interpretar a "nova economia" ligada às TICs, à financeirização e à liberalização das diferentes economias nacionais, da seguinte maneira: a permanência da bolha financeira, nos Estados Unidos, se explica a partir das possibilidades oferecidas pela economia real, no nível mundial. A flexibili-

\footnotetext{
${ }^{38}$ Alain Herscovici, Economia da Cultura e da Comunicação, Fundação Ceciliano Abel de Almeida/ Ufes, Vitória, 1995.

${ }^{39}$ François Chesnais, "Nova economia: uma conjuntura específica da potência hegemônica no contexto da mundialização do capital", in Revista da Sociedade Brasileira de Economia Política, n ${ }^{\circ}$ 9, dezembro de 2001.

${ }^{40}$ A esse respeito, ver Alain Herscovici, Economia da cultura e da comunicação, op. cit., capítulo II, seção II.
} 
zação do trabalho permitida pela introdução dessas TICs e, de uma maneira mais geral, todas as mudanças organizacionais das empresas são fatores reais que se traduzem por um aumento da produtividade do trabalho - da mesma maneira, os mecanismos internacionais característicos desse regime de acumulação permitem realizar uma transferência internacional da mais valia produzida fora dos Estados Unidos. À medida que esse regime de acumulação se baseia sobre a permanência do capital fictício, é preciso haver uma ampliação “(...) de punções parasitárias da finança sobre a economia real” ${ }^{41}$, ou seja, um aumento da taxa de exploração no nível mundial; a maior parte dos dados estatísticos aponta para tal fenômeno.

Os mecanismos nacionais e internacionais que correspondem a esta nova economia permitem realizar essas punções parasitárias por meio do aumento da mais valia realizada; esta se dá, no nível nacional, a partir das novas formas de organização do trabalho permitido pelas TICs e, no nível internacional, pelos mecanismos de transferências da mais valia criada fora dos Estados Unidos, para os Estados Unidos. É possível formular as seguintes conclusões:

i) Em função da nova estruturação do espaço mundial e dos fluxos internacio-nais de capitais, a relativa permanência desse regime de acumulação só é realizável no que diz respeito os Estados Unidos.

ii) Esse regime de acumulação não pode ser considerado como a estrutura deuma nova economia, ou seja, de um novo modo de regulação: primeiro, sua estabilidade depende diretamente da mais valia produzida e realizada no setor produtivo e, nesse sentido, uma diminuição da produtividade do trabalho e/ou do capital ameaça a estabilidade dessa economia financeirizada. Segundo, apesar dos mecanismos que caracterizam essa nova economia, esta continua sendo dependente da economia real, ou seja, das condições de produção, de realização e de transferência internacional da mais valia criada no setor produtivo; a economia real continua impondo os limites a essa economia financeira.

iii) Finalmente, se considerarmos que a ampliação da esfera financeira é assimlimitada, não é possível afirmar que essa nova economia constitui um novo modo de regulação pós-fordista: sua autonomia é limitada pelas condições da economia real mundial - a fase de crescimento que os Estados Unidos conheceram, a partir da segunda metade dos anos 90, se explica a partir de um aumento da produtividade do trabalho no setor produtivo, e não da criação de um novo setor ligado à finança e/ou às TICs, criador de valor em si.

Essa análise corresponde a uma inversão da lógica implícita dessa nova economia: são os ganhos de produtividade do trabalho, ou seja, o aumento da taxa de exploração, que permitem sustentar a existência e permanência dessa economia financeirizada, e não o contrário. Em outras palavras, não é o "dinamismo" da finança que permite sustentar essa fase de crescimento econômico, mas, ao contrário, os ganhos de produtividade realizados no setor produtivo. Da mesma maneira, não são as TICs que, em si, constituem a causa dessa fase de expansão: elas são relati-

${ }^{41}$ François Chesnais, op. cit., p. 75 . O grifo é nosso. 
vamente antigas e apareceram no início dos anos 70. Elas não explicam os ganhos de produtividade recentes da economia americana; o paradoxo de Solow mostra que não existe uma correlação positiva entre os ganhos de produtividade e a taxa de equipamento das firmas em TIC. Essa "nova economia" não criou as formas institucionais adequadas que permitiriam assegurar a perenidade desse regime de acumulação: nesse sentido, Chesnais afirma que esse regime de acumulação se caracteriza “(...) por uma grande fragilidade sistêmica” e é assim reversível ${ }^{42}$.

As TICs representam, sem dúvida, uma inovação, no sentido definido por Schumpeter ${ }^{43}$ : há, simultaneamente, criação de um novo bem, modificação dos métodos de produção e implementação de novas estruturas industriais. Não obstante, elas não constituem um setor motor que permite prever um novo ciclo longo de crescimento, conforme aponta o paradoxo de Solow.

Os efeitos macroeconômicas dessa terceira revolução industrial são profundamente diferentes daqueles das revoluções precedentes: a precariedade do modo de acumulação sob dominância financeira ressalta o fato de que não está havendo compatibilidade, a médio prazo, entre as modalidades de acumulação ligadas à financeirização e as ligadas à produção do excedente. Enquanto essas compatibilidades caracterizavam as duas primeiras revoluções industriais, elas não existem no que diz respeito às TICs.

\section{O paradoxo de Solow: as diferentes interpretações}

O paradoxo de Solow provém do fato de que, nos Estados Unidos e, numa certa medida, nos países europeus, dos anos 70 até a metade dos anos 90, aos investimentos crescentes em TIC corresponde uma queda do ganhos de produtividade do trabalho.

\section{A tese neoclássica da convergência}

No âmbito do modelo de crescimento neoclássico de Solow, a partir de uma abordagem em termos de função de produção agregada, o declínio dos ganhos de produtividade se explicaria pelo fato de os países europeus e do Japão já se terem beneficiado do desvio que eles apresentavam em relação a seu estado estacionário ótimo e terem crescido assim mais rapidamente que os Estados Unidos (a tese da convergência). Não obstante, o valor explicativo desta análise é limitado pelas seguintes razões: (a) à medida que países diferentes têm estados ótimos diferentes, a tese da convergência só se relaciona com países que têm o mesmo estado estacionário ótimo, ou seja, com certos clubes de convergência ${ }^{44}$. Esta análise só teria

\footnotetext{
${ }^{42}$ François Chesnais, op. cit., p. 55.

${ }^{43}$ Joseph Schumpeter, A teoria do desenvolvimento econômico, Nova Cultural, São Paulo, 1985, p. 48.

${ }^{44}$ Pascal Petit, "Crescimento, mudança técnica e mutações setoriais: de uma convergência a uma outra", in Telecomunicações, desregulamentação e convergência tecnológica. Uma análise comparada, J.B. Tapia, e A Rallet (orgs.), Instituto de Economia/Unicamp, Campinas, 1999, p. 204.
} 
validade para os países desenvolvidos, por exemplo ${ }^{45}$. (b) Se restringimos esta análise ao Japão, aos países europeus e aos Estados Unidos, o modelo neoclássico de crescimento permite explicar o declínio dos ganhos de produtividade do Japão e dos países europeus pelo fato de esses países terem esgotado as reservas de crescimento que provinham de seu "atraso" em relação aos Estados Unidos; não obstante, o declínio da produtividade nos Estados Unidos permanece inexplicado ${ }^{46}$.

Assim, a tese do catch-up não permite explicar a totalidade desse fenômeno; a convergência é limitada pelas diferenças institucionais que existem entre os diferentes países ou entre os diferentes grupos de países. Criam-se, assim, clubes tecnológicos de empresas multinacionais, estes sendo constituídos em redes mundiais ${ }^{47}$; são esses clubes tecnológicos que determinam a hierarquia existente nessa nova economia globalizada, ou seja, a formação de determinados clubes de convergên$\mathrm{cia}^{48}$. Finalmente, esses clubes tecnológicos são clubes fechados que se caracterizam por importantes barreiras à entrada; estes correspondem ao conceito de redes fechadas que elaboramos anteriormente.

\section{A análise neo-schumpeterianalinstitucionalista}

Uma interpretação alternativa é a seguinte: a implementação de um novo sistema tecnológico implica modificações institucionais, organizacionais e ligadas às qualificações dos trabalhadores. Essas evoluções são relativamente lentas e constituem a condição a partir da qual as TICs começariam a se tornar produtivas. Essa queda dos ganhos de produtividade se explicaria pelo fato de o sistema não ter "absorvido", ainda, essas novas tecnologias; trata-se de um processo clássico de aprendizagem em relação ao uso dessas novas tecnologias. É possível sustentar tal tese a partir de uma abordagem neo-schumpeteriana e/ou institucionalista; não obstante, essas modalidades de aprendizagem não são as mesmas para o conjunto dos países.

Nesta perspectiva, certos autores desenvolvem os conceitos de apropriabilidade $e$ de acessibilidade ${ }^{49}$. A acessibilidade se relaciona com a difusão das novas tecnologias e, entre outras, das TICs; a apropriabilidade está diretamente ligada aos diferentes arranjos institucionais que permitem se aproveitar de sinergias provendo da constituição de redes semifechadas. A apropriabilidade expressa as diferentes modalidades de apropriação e de aproveitamento dos sistemas tecnológicos ligados às TICs; cada clube de convergência caracteriza-se por modalidades dife-

\footnotetext{
${ }^{45}$ Mankiw N. G., Romer D., Weil D., “A contribution to the empirics of economic growth”, Quartely Journal of Economics, 107 (maio).

${ }^{46}$ Francisco Lima Teixeira, "Tecnologia, organizações e produtividade: lições do paradoxo de Solow”, Revista de Economia Política, vol. 21, nº 2 (82), abril-junho/2001, p. 136.

${ }^{47}$ Pascal Petit, op. cit., p. 207.

${ }^{48}$ Idem, p. 207.

${ }^{49}$ Ibid., p. 205.
} 
renciadas de internalização das externalidades geradas pelo sistema tecnológico ligado às $T I C s^{50}$. Esse resultado tem as seguintes implicações: (a) não pode haver uma convergência absoluta entre os diferentes países à medida que, mesmo se as condições de acessibilidade são semelhantes para os diferentes países, as condições de apropriabilidade são diferenciadas; (b) a convergência limitada explica-se a partir da hierarquização do espaço mundial em zonas que têm condições diferenciadas de apropriabilidade; (c) a existência de externalidades provém da constituição de redes dentro das quais circulam informações e, entre outras, informações tecnológicas; as desigualdades e a estruturação hierarquizada do espaço mundial explicam-se a partir das modalidades diferenciadas de apropriabilidade das externalidades geradas por esse sistema tecnológico. Essa internalização diferenciada das externalidades permite explicar as diferenças entre os diferentes grupos de países e a existência de pólos dominantes.

\section{Outras análises}

A partir de uma perspectiva semelhante, é possível afirmar que as TICs constituem um instrumento que permite aumentar a competitividade das empresas, sem que isso se traduza em um aumento da produtividade do trabalho ${ }^{51} \mathrm{em}$ nível agregado; neste caso, trata-se de processos de reestruturação dos mercados, os quais se traduzem em uma concentração maior e não têm impacto sobre a produtividade global do trabalho do setor considerado. Estamos na presença do seguinte paradoxo: por um lado, conforme reconhecem vários autores, as novas formas de competitividade das empresas mudaram: não se trata de realizar economias de escalas no que diz respeito a uma produção industrial ${ }^{52}$, mas muito mais de diferenciar produtos e modalidades de acesso aos mercados e aos públicos segmentados. Isso corresponde a uma transformação das formas concretas da concorrência capitalista, mais especificamente a uma oligopolização crescente dos diferentes mercados: a concorrência não se expressa mais ao nível dos $\operatorname{preços}^{53}$.

Por outro lado, o desenvolvimento desses gastos improdutivos, apesar de eles serem necessários, não é mais compatível com a queda dos ganhos de produtividade do trabalho, ou seja, com o excedente realizado no setor produtivo ${ }^{54}$. O processo descrito aqui é semelhante ao descrito por François Chesnais, no que diz respei-

\footnotetext{
${ }^{50}$ Ibid., p. 208.

${ }^{51}$ Fransisco Lima Teixeira, “Tecnologia, organizações e produtividade: lições do paradoxo de Solow”, op. cit., pp. 144 e 145.

52 Jean Lojkine, “Marx après Marx. Le marxisme face à la révolution informationnelle”, in L'ordre capitaliste, PUF, Paris, 1996, p. 45.

${ }^{53}$ No que diz respeito a uma análise detalhada, ver nosso livro Economia da cultura e da comunicação, op. cit.

${ }^{54}$ Para uma apresentação detalhada formalizada deste argumento, ver Alain Herscovici, Trabalho improdutivo e crescimento de longo prazo. Um modelo clássico de acumulação”, Revista de Economia Política, $3^{\circ}$ trimestre 1996, São Paulo, 1996.
} 
to ao regime de acumulação sob dominância financeira: "A alta da produtividade do capital e a alta da taxa de exploração são as condições permissivas (...)" que permitem explicar a permanência da bolha financeira e, entre outros, da NASDAQ até o final do ano $2000^{55}$.

\section{CONCLUSÃO}

Como conclusão, é possível afirmar que a economia das redes eletrônicas e do modo de regulação no qual ela está inserida apresenta as seguintes características:

i) por um lado, ela se traduz em importantes movimentos de concentração e as situações de mercado não correspondem a situações concorrenciais, seja em relação à concepção walrasiana ou ao grau de contestabilidade dos mercados. Por outro, conforme aponta o surgimento dos programas livres, aparecem novas formas de concorrência e de reapropriação da Informação; ii) essa economia se traduz, igualmente, em novas articulações entre o mercantil e o não-mercantil e, de uma maneira mais geral, em novos arranjos institucionais, seja no seio da própria economia dessas redes, seja no que diz respeito às estruturas econômicas globais: modalidades de acesso aos mercados, flexibilização dos processos espaciais de produção e flexibilização dos diferentes mercados do trabalho; iii) não obstante, do ponto de vista macroeconômico, não apareceram as coerências institucionais necessárias que permitiriam implementar um novo modo de regulação, no sentido empregado pela Escola Francesa da Regulação.

\section{BIBLIOGRAFIA}

AKERLOF, G., “The market for 'lemons': qualitative uncertainty and the market mechanism”, Quarterly Journal of Economics, Aug. 1970, 89.

AMABLE, Bruno e PETIT, Pascal, “Ajustamento estrutural e política industrial: uma abordagem regulacionista”, in Bruno Théret e José Carlos de Souza Braga (orgs.), Regulação econômica e globalização, IE/Unicamp, Fundap, Campinas, 1998.

ARROW, Kenneth J., "Limited knowledge and economic analysis", American Economic Review, March 1974.

"De la rationalité de soi et des autres dans un système économique", in Théorie de l'information et des organisations, Edité et présenté par Thierry Granger, Dunod, Paris, 2000.

, "L'économie de l'information: un exposé", in Théorie de l'Information et des organisations, Edité et présenté par Thierry Granger, Dunod, Paris, 2000.

, "Potentialités et limites du marché dans l'allocation des ressources", in Théorie de l'information et des organisations.

BAUMOL, W., "Contestable markets: an uprising in the theory of industry structure", American Economic Review, vol. 72, n 1, 1982.

BESSON, Jean-François, Economie publique. L'échange sans marché, PUF, Paris, 1978.

BROUSSEAU, Eric, "Intermédiation par les réseaux: quelles institutions?”, in Mutations des télécom-

${ }^{55}$ François Chesnais, op. cit., p. 75. 
munications, des industries et des marchés, E. Brousseau, P. Petit et Denis Phan (orgs.), ENSPTT/ Economica, Paris, 1996.

CHESNAIS, François, "Nova economia: uma conjuntura específica da potência hegemônica no contexto da mundialização do capital", in Revista da Sociedade Brasileira de Economia Política, $\mathrm{n}^{\circ}$ 9, dezembro de 2001.

COHEN Daniel, DEBONNEUIL Michèle, "L'économie de la nouvelle économie", in Nouvelle economie, conseil d'analyse economique, La Documentation Française, Paris, 1998.

CURIEN, Nicolas, Economie des réseaux, La Découverte, Paris, 2000.

FAVEREAU, Olivier, "Notes sur la théorie de l'information à laquelle pourrait conduire l'économie des conventions", in L'economie de l'information, sous la direction de Pascal Petit, La Découverte, Paris, 1998.

, "L'économie des conventions: son objet, sa contribution à la science économique", Problèmes économiques, $\mathrm{n}^{\circ}$ 2167, 21 Mars 1990, La Documentation Française, Paris.

GROSSMAN, S. J. and J. E. STIGLITZ, "Information and competitive price system”, American Economic Review, May 76, vol. 66, $\mathrm{n}^{\circ} 2$.

HERSCOVICI, Alain, "Economia do desequilíbrio, sistema de preços e instituições: elementos de análise", in Ensaios FEE, vol. 23, n 1, 2002, Porto Alegre.

, Dinâmica macroeconômica: uma interpretação a partir de Marx e de Keynes, Educ/Edufes, São Paulo, 2002.

, Economia da cultura e da comunicação, Fundação Ceciliano Abel de Almeida/Ufes, Vitória, 1995.

, "Trabalho improdutivo e crescimento de longo prazo. Um modelo clássico de acumulação", Revista de Economia Política, vol. 16, nº 3 (63), julho-setembro/1996,.

HODGSON, Geoffrey M., "The Approach of Institucional Economics”, Journal of Economic Litterature, vol. 36, Issue 1, March 1998.

KEYNES, John Maynard, A teoria geral do emprego, do juro e da moeda, Atlas, São Paulo, 1990.

LE MOIGNE, Jean-Louis, "La modélisation systémique de l'Information", in L'economie de l'information, op. cit.

LIMA TEIXEIRA, Francisco, "Tecnologia, organizações e produtividade: lições do paradoxo de Solow", Revista de Economia Política, vol. 21, nº 2 (82), abril-junho/2001.

LOJKINE, Jean, "Marx après Marx. Le marxisme face à la révolution informationnelle", in L'ordre capitaliste, PUF, Paris, 1996.

MANKIW, N. Gregory, "Small menu cand large business cycles: a macroeconomic model of monopoly", Quartely Journal of Economics 100, 1985.

MANKIW N.G., ROMER D., Weil D., “A contribution to the empirics of economic growth”, Quartely Journal of Economics 107 (maio).

MOURA FERREIRA JÚNIOR, Hamilton de, COSTA VARGENS FILHO, José Rogério da, "O preço do unbundling no Brasil. Concorrência e universalização na indústria de telecomunicações”, Revista de Economia Contemporânea, vol. 6, $\mathrm{n}^{\circ}$ 1, janeiro-junho de 2002, Rio de Janeiro.

PETIT, Pascal, "Crescimento, mudança técnica e mutações setoriais: de uma convrgência a uma outra" in Telcomunicações, desregulamentação e convergência tecnológica. Uma análise comparada, J. B. Tapia, e A. Rallet (orgs.), Instituto de Economia/Unicamp, Campinas, 1999.

QUÉAUD, Philippe, “Les termes inégaux de l'échange électronique”, Le Monde Diplomatique, Février 1999.

RALLET, Alain, "A teoria das convenções segundo os economistas", in Nexos, vol. I, n 2, dezembro de 1999, Salvador.

SALOP, Steve, "Information and Monopolistic Competition", American Economic Review, vol. 66, $\mathrm{n}^{\circ}$ 2, May 1976.

SCHUMPETER, Joseph, A teoria do desenvolvimento econômico, Nova Cultural, São Paulo, 1985. 